\title{
Long term results of reoperations for recurrent angina with internal mammary artery versus saphenous vein grafts
}

\author{
D Dougenis, A H Brown
}

\begin{abstract}
Objective-To evaluate the long term results of coronary reoperations for recurrent angina with internal mammary (thoracic) arteries versus vein grafts.

Design-Inception cohort of 103 patients with a mean follow up of 7.1 years (range 1.0-11.6).

Setting-Regional cardiothoracic centre. Patients-Among 103 consecutive patients, mean (SD) age 61.8 (9.7) years, who were reoperated for recurrent angina between January 1982 and December 1991, 53 patients had unilateral or bilateral internal mammary artery (IMA) grafting supplemented or not with saphenous vein (SV) grafts (group A), and 50 patients underwent reoperative coronary surgery using SV grafts only (group B). The two groups were comparable in terms of demographic and clinicopathological data.
\end{abstract}

Measurements and results-Operative mortality was $5.6 \%$ (95\% confidence interval 4.6 to 6.6) for group $A$, and $10 \%$ (8.2 to 11.8) for group $B(p>0.05)$. Probability of freedom from new recurrence of angina was $86 \%$ at 5 and 10 years in group $A$, compared with $56 \%$ and $25 \%$ respectively in group $B(p=0.005)$. Freedom from cardiac events was estimated to be $81 \%$ at 5 and 10 years in group $A, v 52 \%$ and $20 \%$ for group B, respectively. Actuarial survival was $95 \% v 93 \%$ at 3 years, $95 \% v 85 \%$ at 5 years, and $88 \% v 71 \%$ at 10 years after reoperation $(p>0.05)$.

Conclusions-The long term results of IMA are superior to $\mathrm{SV}$ grafts in terms of freedom from new recurrence of angina and other cardiac events. The IMA is thus the conduit of choice in coronary revascularisation.

(Heart 1998;80:9-13)

Keywords: coronary artery bypass; coronary reoperation; recurrent angina; internal thoracic (mammary) artery

During the past 20 years in coronary artery surgery, the most important development has been the employment of the internal mammary artery (IMA) as a conduit. ${ }^{1}$ The IMA has been found to be a superior conduit in first time coronary artery bypass grafting (CABG); compared with vein conduits, it has significantly reduced hospital mortality and probability of coronary artery reoperation. ${ }^{2-4}$ Furthermore, when reoperation is indicated because of the failure of other grafts or progressive atherosclerosis, a patent IMA does not increase the risk of reoperation and additional IMA grafting at reoperation does not increase the hospital morbidity or early mortality. ${ }^{5}$

Although most surgeons appreciate that the IMA is the conduit of choice in the primary operation, there is reluctance to use IMA grafts in reoperations (which play an increasing role in coronary artery surgery) on patients in whom neither IMA, or only one, was used at the first operation. Previous studies ${ }^{6-14}$ have addressed the efficacy and role of IMA grafts in repeat CABG, but there is still limited documentation of the long term results - at 10 years-by means of actuarial survival and event-free probability. In this report, we compare the early and late results of IMA versus saphenous vein grafting in reoperations for recurrent angina, and concentrate on the freedom from cardiac events, long term survival, and the probability of further recurrence of angina after a successful second operation.

\section{Methods}

Between January 1981 and December 1990, 103 consecutive patients with recurrent angina after previous coronary grafting underwent repeat myocardial revascularisation procedures performed under the care of one surgeon (AHB). There were 82 men and 21 women, none having had an IMA graft at the primary operation. Their mean (SD) age was 61.8 (9.7) years, range 43 to 71 .

The patients were divided into two groups according to whether, at reoperation, an IMA graft was used as a conduit. Group A consisted of 53 patients $(51 \%)$, mean age $59.8(10.8)$ years, submitted to unilateral $(40(75 \%))$ or bilateral (13 (25\%)) IMA grafting, supplemented or not with saphenous vein (SV) grafts; group B comprised 50 patients $(49 \%)$, mean age 63 (8.8) years, who had only SV grafts.

Demographic and clinicopathological data, and predisposing factors for both groups are given in tables 1 and 2 . After reviewing the angiographic data, the causes of reoperation in groups A and B, respectively, were as follows: patent atherosclerotic (stenotic) vein graft disease in $37 \%$ and $46 \%$, graft blockage in $33 \%$ and $22 \%$, and progression or new native disease in $28 \%$ and $30 \%$. Triple vessel disease was identified in $64 \%$ and $60 \%$ respectively. The mean time elapsed between first operation and angina recurrence was 57.3 months for group A and 61.4 months for group B. The 
Table 1 Distribution of demographic and clinicopathological characteristics of the two groups of patients

\begin{tabular}{|c|c|c|c|}
\hline \multirow[b]{2}{*}{ Age (years) } & $\begin{array}{l}\text { Group A } \\
(n=53)\end{array}$ & $\begin{array}{l}\text { Group B } \\
(n=50)\end{array}$ & \multirow{2}{*}{$\frac{p \text { valu }}{0.10}$} \\
\hline & $59.8(10.8)$ & $63(8.8)$ & \\
\hline \multicolumn{4}{|l|}{ Sex } \\
\hline Male & 43 & 39 & 0.69 \\
\hline Female & 10 & 11 & \\
\hline Angina-free interval after 1 st CABG (months) & $57.3(18)$ & $61.4(24)$ & 0.37 \\
\hline Time from 1 st to 2 nd operation (months) & $61.2(23.4)$ & $65.4(32)$ & 0.17 \\
\hline \multicolumn{4}{|l|}{ Left ventricular function } \\
\hline Good & $30 \quad(57)$ & $20 \quad(40)$ & 0.09 \\
\hline Fair & 16 (30) & 19 & 0.40 \\
\hline Poor & $7 \quad(13)$ & 11 & 0.49 \\
\hline Left main disease & $7 \quad(13)$ & $6 \quad(12)$ & 0.34 \\
\hline Triple vessel disease & $34 \quad(64)$ & $30 \quad(60)$ & 0.66 \\
\hline Urgent surgery & $8 \quad(15)$ & 10 & 0.51 \\
\hline No of grafts at 1 st operation & $3.1(1)$ & $3.2(1.2)$ & 0.56 \\
\hline No of grafts at 2 nd operation & $2.8(0.9)$ & $3(1.1)$ & 0.34 \\
\hline \multicolumn{4}{|l|}{ Angiographic data } \\
\hline Graft blockage & $18 \quad(33)$ & $11 \quad(22)$ & 0.61 \\
\hline Atherosclerotic vein graft disease & $20 \quad(37)$ & $23(46)$ & 0.39 \\
\hline Progression/new disease & $15 \quad(28)$ & $15 \quad(30)$ & 0.85 \\
\hline Incomplete revascularisation & 1 (2) & 1 (2) & 0.73 \\
\hline
\end{tabular}

Group A, IMA grafts (with or without SV grafts); group B, SV grafts only. Values are expressed as mean (SD), and number of patients (\%). There were no significant differences between the groups.

Table 2 Distribution of predisposing factors between the two groups of patients at the time of reoperation

\begin{tabular}{lccc}
\hline & Group A & Group B & p value \\
\hline Smoking & $8(15)$ & $7(14)$ & 0.87 \\
Obesity & $16(30)$ & $12(24)$ & 0.48 \\
Hypertension & $4(7)$ & $5(10)$ & 0.74 \\
Hyperlipidaemia & $4(7)$ & $4(8)$ & 0.93 \\
Diabetes mellitus & $3(6)$ & $5(10)$ & 0.48 \\
Family history of ischaemic heart disease & $17(32)$ & $16(32)$ & 0.99 \\
\hline
\end{tabular}

Group A, IMA grafts (with or without SV grafts); group B, SV grafts only. Values are expressed as number of patients (\%). There were no significant differences between the two groups.

time intervals between first and second operations were 61 and 65 months, respectively. Predisposing factors for coronary artery disease were identified in a large proportion of patients in both groups (table 2): a family history of ischaemic heart disease was present in $32 \%$ of both groups, while hypertension and hyperlipidaemia were present in $7 \%$ and $10 \%$ of patients in group $\mathrm{A}$, and $7 \%$ and $8 \%$ of those in group $B$, respectively.

Moderate hypothermia $\left(28^{\circ} \mathrm{C}\right)$ and crystalloid cardioplegic arrest were standard techniques at reoperation, where complete revascularisation was attempted in all cases. IMA grafts were harvested as previously described. ${ }^{15}$ In group A, a left IMA graft to the left anterior descending coronary artery was used in 40 patients; in three, the first diagonal was also bypassed in a sequential anastomosis. The right IMA was used to bypass the proximal right coronary artery in three, the posterior descending coronary artery in nine, or the obtuse marginal artery in one. Six patients had only arterial grafts. At reintervention, a mean of 2.8 grafts per patient (148/53) and 3.0 per patient $(151 / 50)$ were inserted in groups $A$ and B, respectively. Eight patients (15\%) from group A and 10 (20\%) from group B had urgent operations for unstable recurrent angina.

Both procedures were performed during the same time period. During the first three years of the study, only SV grafts were used. Subsequently, IMA grafting was introduced in coronary reoperations. No particular selection of patients to receive IMA was made, but those with mediocre preoperative lung function, obesity, and diabetes mellitus were more likely to have SV grafting only. All patients were followed up by the referring cardiologists unless there were problems requiring surgical attention. Complete follow up was achieved over a period of between 11 and 136 months, mean 7.1 years.

STATISTICAL ANALYSIS

Dichotomous variables are expressed as numbers of patients and continuous variables as means (SD). Comparisons between the two groups were made with the $t$ test, the $\chi^{2}$ test, and Fisher's exact test as required. Actuarial and event-free survival figures were obtained by the Kaplan-Meier product-limit method. ${ }^{16}$ Comparisons were made by the log-rank test, ${ }^{17}$ using the Biomedical Data Processing statistical package. Ninety five per cent confidence intervals $(95 \% \quad \mathrm{CI})$ were calculated for mortality, event-free, and actuarial survival rates. Probability (p) values $<0.05$ were considered significant.

\section{Results}

GROUP COMPATIBILITY

Although patients receiving IMA grafts tended to be younger (mean age $59.8 v 63$ years), this difference was not significant $(0.1>\mathrm{p}>0.05)$. There was also no significant difference between the two groups with respect to other demographic and clinicopathological data. Thus the groups were considered compatible for the rest of our analyses.

\section{EARLY RESULTS}

Mortality

There were three deaths in group A, and five in group B. For the entire population, the overall hospital mortality (30 day mortality, or at any time if the patient remained in hospital more than 30 days) was $7.8 \%$ (95\% CI 6.4 to 9.2 ); $5.6 \%$ (4.6 to 6.6 ) for group A and $10 \%$ (8.2 to $11.8)$ for group $B(p>0.05)$. In group $A$, the causes of death were perioperative myocardial infarction in two patients and acute traumatic dissection of the right internal mammary artery $^{18}$ in one. The causes of death in the patients in group B were myocardial infarction and low cardiac output state in three, postoperative stroke in one, and pulmonary sepsis following prolonged ventilation for respiratory failure in one.

\section{Morbidity}

Table 3 summarises the postoperative complications. Perioperative myocardial infarction occurred in $6 \%$ of the patients in the IMA group and in $14 \%$ in the SV group. Reopening for bleeding was required in $8 \%$ and $4 \%$, respectively, while wound complications developed in three patients and one patient, respectively. None of the differences in the morbidity rate between the two groups was significant, although wound complications and postoperative bleeding were observed more often in the IMA group, while the incidence of myocardial infarction was higher in the SV group. 
Table 3 Distribution of complications between the two groups

\begin{tabular}{llll}
\hline & Group A & Group B & $\begin{array}{l}p \\
\text { value }\end{array}$ \\
\hline Myocardial infarction & $3(6)$ & $7(14)$ & 0.11 \\
Reopening for bleeding & $4(8)$ & $2(4)$ & 0.36 \\
Wound infection & $3(8)$ & $1(2)$ & 0.33 \\
Supraventricular arrhythmia & $4(8)$ & $5(10)$ & 0.94 \\
Pulmonary complications & $7(13)$ & $5(10)$ & 0.76 \\
Neurological deficit & $2(4)$ & $4(8)$ & 0.42 \\
Low cardiac output state & $7(13)$ & $4(8)$ & 0.52
\end{tabular}

Group A, IMA grafts (with or without SV grafts); group B, SV grafts only. Values are expressed as number of patients (\%). There were no significant differences between the groups.

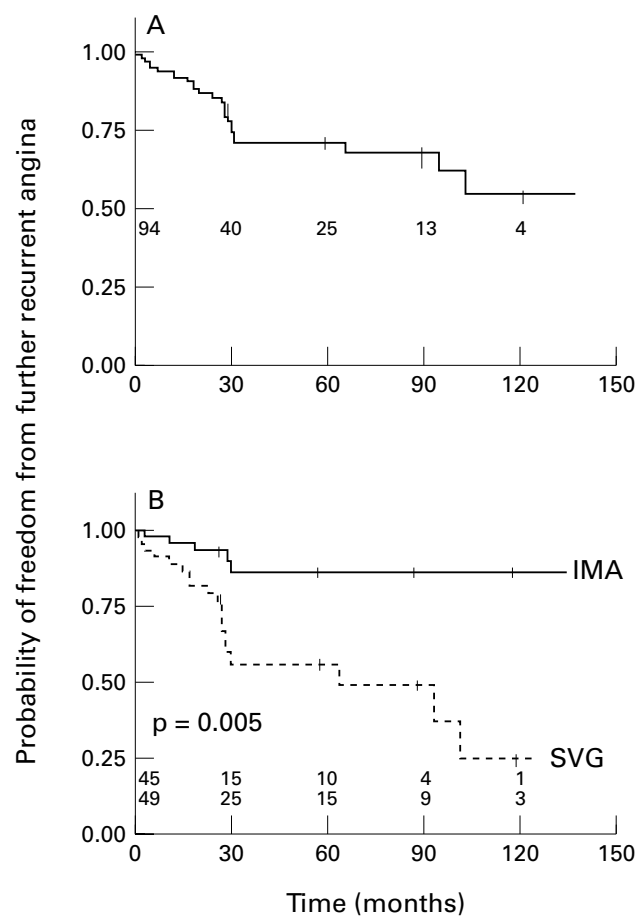

Figure 1 (A) Kaplan-Meier product probability of freedom from recurrent angina for the entire study population. (B) Comparison between the internal mammary and saphenous vein groups of patients. $I M A$, internal mammary artery; SVG, saphenous vein graft. Numbers of patients at risk are also shown.

LATE RESULTS

Recurrent angina

Among the 50 and 45 survivors, respectively, in groups A and B, 24 patients (25\%) developed further recurrent angina during the follow up period, despite a successful second operation.
For the entire study population, the 3, 5, and 10 year figures for freedom from recurrent angina were $71 \%, 71 \%$, and $54 \%$, respectively (fig 1A; table 4). However, the probability of freedom from recurrent angina in the patients in group A was estimated at $86 \%$ at 3, 5, and 10 years, as compared with $56 \%, 56 \%$, and $25 \%$ for those in group B (fig 1B; table 4). This difference was highly significant $(p=0.005)$.

\section{Event-free analysis}

Overall freedom from cardiac events (including further recurrent angina, death, and subsequent myocardial revascularisation procedure or heart transplant) was estimated at $67 \%$, $67 \%$, and $50 \%$ at 3,5 , and 10 years after the second operation (fig $2 \mathrm{~A}$; table 4 ). For group A, this was $81 \%$ at 5 and 10 years, compared with $52 \%$ and $20 \%$ for group B (fig 2 ; table 4 ). Patients having IMA grafting at reoperation had a greatly increased probability of freedom from cardiac events $(p=0.0009)$.

\section{Late survival}

For the entire group, the overall late survival rates among the operative survivors were $91 \%$, $88 \%$, and $80 \%$ at 3,5 , and 10 years after reoperation (fig 3; table 4). Survival was $95 \%$ for group A v 93\% for group B at 3 years, 95\% v $85 \%$ at 5 years, and $88 \%$ v $71 \%$ at 10 years, respectively. Although late survival was better for patients receiving IMA grafts at reoperation, this difference did not reach significance (fig 3B; table 4).

\section{Discussion}

Reoperation for coronary artery disease has become a standard procedure, accounting for approximately $6 \%$ to $10 \%$ of all coronary bypass operations performed annually. ${ }^{19}{ }^{20}$ For those surviving up to 15 years after CABG, the incidence of reoperation approaches $38 \%$, and the main cause of reintervention is the development of vein graft atherosclerosis. ${ }^{20}{ }^{21}$ Despite an increased operative mortality and a possibly decreased postoperative benefit, ${ }^{22}{ }^{23}$ it has been well documented that reoperation is a safe and appropriate strategy that improves the survival of patients with late vein graft stenoses, and gives satisfactory symptomatic improvement. ${ }^{892425}$

Table 4 Probability of freedom from recurrent angina and cardiac events, and actuarial survival for the overall population study, and groups $A$ and $B$

\begin{tabular}{|c|c|c|c|c|}
\hline & Overall $(95 \% C I)$ & Group $A(95 \%$ CI $)$ & Group B $(95 \%$ CI $)$ & $p$ value \\
\hline \multicolumn{4}{|c|}{ Freedom from recurrent angina } & \multirow[t]{5}{*}{0.005} \\
\hline 2 year & $86(79$ to 93$)$ & $93(86$ to 100$)$ & $78(67$ to 89$)$ & \\
\hline 3 year & $71(60$ to 82$)$ & 86 (69 to 100$)$ & $56(41$ to 71$)$ & \\
\hline 5 year & $71(60$ to 81$)$ & $86(69$ to 100$)$ & $56(41$ to 71$)$ & \\
\hline 10 year & $54(36$ to 72$)$ & $86(69$ to 100$)$ & $25(1$ to 50$)$ & \\
\hline \multicolumn{4}{|c|}{ Freedom from cardiac events } & \multirow[t]{5}{*}{0.0009} \\
\hline 2 year & $84(76$ to 92$)$ & 88 (78 to 98$)$ & $78(67$ to 89$)$ & \\
\hline 3 year & $67(59$ to 75$)$ & $81(70$ to 82$)$ & $52(35$ to 79$)$ & \\
\hline 5 year & $67(59$ to 75$)$ & $81(70$ to 82$)$ & $52(35$ to 79$)$ & \\
\hline 10 year & $50(33$ to 67$)$ & $81(70$ to 82$)$ & $20(1$ to 39$)$ & \\
\hline \multicolumn{4}{|c|}{ Actuarial survival } & \multirow[t]{4}{*}{0.2} \\
\hline 3 year & $91(83$ to 99$)$ & 95 (88 to 100$)$ & 93 (86 to 100$)$ & \\
\hline 5 year & $88(80$ to 96$)$ & 95 (88 to 100$)$ & $85(72$ to 98$)$ & \\
\hline 10 year & $80(69$ to 91$)$ & 88 (75 to 100$)$ & $71(52$ to 90$)$ & \\
\hline
\end{tabular}

Group A, IMA grafts (with or without SV grafts); group B, SV grafts only. CI, confidence interval. 


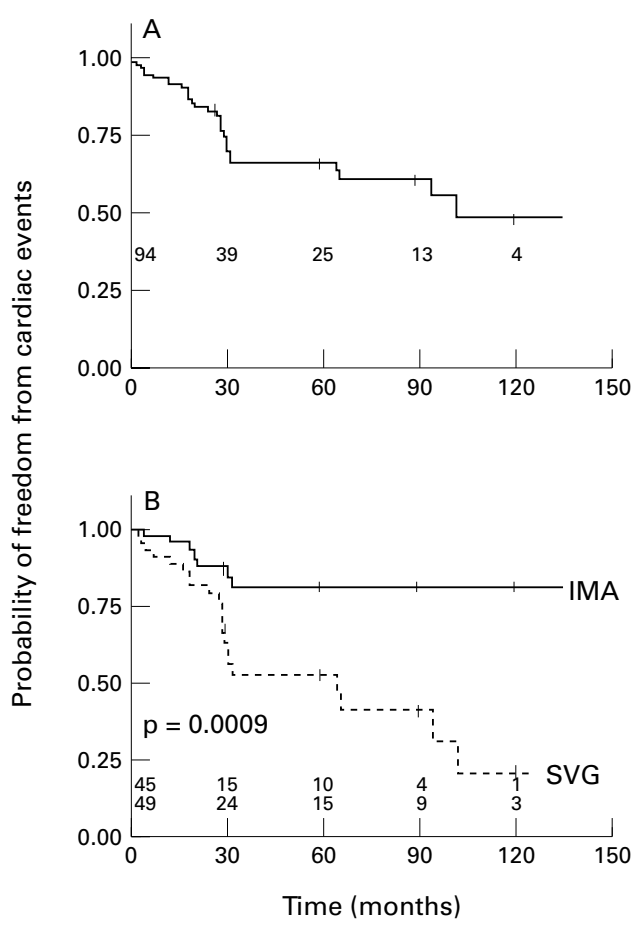

Figure 2 (A) Kaplan-Meier product probability of freedom from cardiac event for the entire population study. (B) Comparison between the internal mammary artery and saphenous vein groups of patients. IMA, internal mammary artery; SVG, saphenous vein graft. Numbers of patients at risk are also shown.

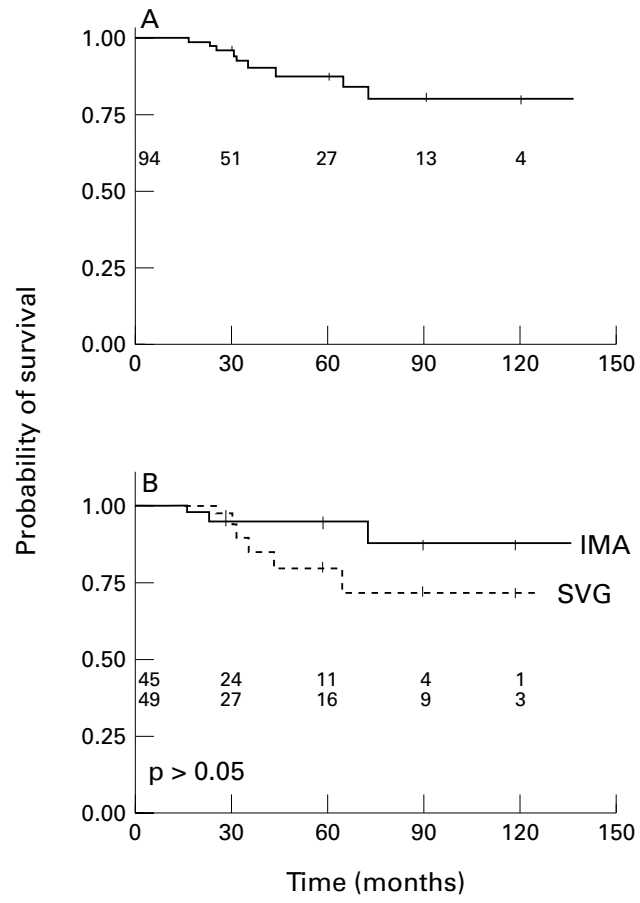

Figure 3 (A) Actuarial (Kaplan-Meier) survival for the entire population study. (B) Comparison of survival

between the internal mammary artery and saphenous vein groups of patients. IMA, internal mammary artery; SVG, saphenous vein graft. Numbers of patients at risk are also shown.

There is no doubt that the internal mammary artery is a durable biological conduit for myocardial revascularisation. ${ }^{26}$ In a 15 year follow up of patients who underwent IMA grafting at primary operation, Cameron and colleagues $^{27}$ found that IMA grafting reduced the risk of dying by a factor of 0.73 , and was a significant predictor of late survival. The IMA graft is therefore a powerful surgical tool and should not be withheld from any subgroup of patients, including those undergoing reoperation. We started using bilateral IMA conduits in reoperations, complemented with SV grafts, in 1984. During the latter years of this study period, IMA grafting has become our surgical technique of choice.

In this report, we compared the long term results of IMA versus SV grafts in two otherwise homogeneous and statistically compatible groups of patients requiring reoperation between 1981 and 1991. The overall operative mortality was $7.8 \%$, and perioperative myocardial infarction was the most common severe complication. Others ${ }^{5}{ }^{28-30}$ have reported a reoperative mortality rate ranging from $3.7 \%$ to $13 \%$ in the presence of patent atherosclerotic vein grafts. It is notable that our operative mortality tended to be lower in patients receiving an IMA graft $(5.6 \%)$ than in those having SV grafts only $(10 \%, \mathrm{p}>0.05)$. This probably reflects the increasing experience with IMA grafting in reoperations during the latter years of our study.

Despite the relatively small sample of patients - which represents a potential limitation of our study - we were able to show that, in reoperations, the long term results of IMA grafts were superior to SV grafts, as has been shown with primary operations. Freedom from cardiac events was $81 \%$ at 5 and 10 years following reintervention, compared to $52 \%$ and $20 \%$ in SV grafts group $(p=0.0009)$. Furthermore, freedom from development of recurrent angina was significantly increased in the IMA group ( $86 \%$ at 5 and 10 years) compared with the SV group (56\% and $25 \%$ respectively, $p=0.005)$. These results indicate that IMA grafting in reoperations substantially improves both early and late results.

Surprisingly, however, we failed to detect a significant difference in terms of late survival between the two groups; excluding in-hospital mortality, actuarial survival, although better (95\% and $88 \% v 85 \%$ and $71 \%$ at 5 and 10 years, respectively), failed to reach significance. Nevertheless, a similar observation has been recently reported by Galbut et al..$^{9}$ They evaluated 88 patients who underwent coronary bypass reoperations with bilateral IMA grafts, and 88 computer matched patients receiving SV grafts, and observed a $91.6 \%$ v $85.3 \%$ survival at 5 years (NS). Thus the pattern of long term survival was similar in the two groups.

It has been postulated in the past that patients undergoing coronary reoperations have less relief of angina than patients having primary revascularisation. Loop ${ }^{31}$ reported an approximately $50 \%$ rate of recurrent angina 10 years after reoperative surgery in a large series of patients. Similarly, Cameron and colleagues ${ }^{22}$ reported that $66 \%$ of such patients had recurrent angina, compared with $35 \%$ of patients with primary revascularisation followed up to 5 years. In contrast, this study showed a substantially better result in terms of angina 
relief at 10 years from reoperation when one or both IMAs were used, alone or in conjunction with supplementary SV grafts. In addition, we $\mathrm{e}^{32}$ have previously shown that only for those relatively young patients undergoing IMA grafting at reoperation does second time CABG become a cost-effective procedure, enabling patients to return to work.

The frequency of reoperations for clinically symptomatic patients is increasing in particular among those who had no arterial grafts at primary surgery. There are some situations in which reoperation with IMA grafts is not recommended: patients with radiation induced atherosclerosis; those with extensive brachiochephalic atherosclerosis including the aorta and the innominate, carotid, and proximal subclavian systems, which may also cause a subclavian steal phenomenon; those with patent large diameter, atherosclerotic vein grafts, the replacement of which with smaller diameter IMA might result in hypoperfusion ${ }^{26}$; and those whose IMA grafts were damaged during the primary operation or who suffered severe wound infection and mediastinitis. As the sternal blood supply in patients with diabetes is not compromised, ${ }^{33}$ diabetes should be not be considered an absolute contraindication to the use of IMA grafting at reoperation. In the absence of either internal mammary artery, the use of another arterial conduit must be considered, such as the right gastroepiploic artery, the inferior epigastric artery, or the radial artery.

In conclusion, our study showed that compared with SV grafts, the use of IMA grafts in reoperative coronary surgery is associated with lower early mortality and a significantly increased interval before recurrence of cardiac events or angina. We recommend, therefore, the use of the IMA as the conduit of choice in reoperations for myocardial revascularisation.

1 Dargie HJ. Late results following coronary artery bypass grafting. Eur Heart f 1992;13(suppl H):89-95.

2 Loop FD, Lytle BW, Cosgrove DM, et al. Influence of the internal mammary artery graft on 10-year survival and other cardiac events. $N$ Engl f Med 1986;314:1-6.

3 Zeff RH, Kongtahworn C, Iannone LA, et al. Internal mammary artery versus saphenous vein graft to the left anterior descending coronary artery: prospective randomized study with 10-year of follow-up. Ann Thorac Surg 1988;45:533-6.

4 Edwards FH, Clark RE, Schwartz M. Coronary artery bypass grafting: the Society of Thoracic Surgeons Nationa Database experience. Ann Thorac Surg 1994;57:12-19.

5 Lytle BW, McElnoy D, McCarthy P, et al. Influence of arterial coronary bypass grafting on the mortality in coronary ardiovasc Surg 1994;107:657-82.

6 Verheul HA, Moulijn AC, Hondema S, et al. Late results of 200 repeat coronary artery bypass operations. Am f Cardiol 1991;67:24-30.

7 Loop FD, Lytle BW, Cosgrove DM. Bilateral internal thoracic artery grafting in reoperations. Ann Thorac Surg 1991;52:3-4.
8 Lytle BW, Loop FD, Taylor PC, et al. The effect of coronary reoperation on the survival of patients with stenoses in saphenous vein bypass grafts to coronary arteries. F Thorac Cardiovasc Surg 1993;105:605-14.

9 Galbut DL, Traad EA, Dorman MJ. Bilateral internal mammary artery grafts in reoperative and primary coronary bypass surgery. Ann Thorac Surg 1991;52:20-8.

10 Turner FE, Lytle BW, Navia D, et al. Coronary reoperation: results of adding an internal mammary artery graft to a stenotic vein graft. Ann Thorac Surg 1994;58:1353-4.

11 Navia D, Cosgrove DM, Lytle BW, et al. Is the internal thoracic artery the conduit of choice to replace a stenotic vein graft? Ann Thorac Surg 1994;57:40-4.

12 Gallotti R, Mamolo G, Casucci R, et al. Reoperation for myocardial revascularization using the internal mammary artery. 7 Cardiovasc Surg 1991;32:8-11.

13 Cameron A, Green GE, Kemp HG. Role of internal mammary artery in reoperation for coronary artery disease. $A d v$ Cardiol 1988;36:84-9.

14 Green GE. Reoperations and the internal mammary artery. Adv Cardiol 1988:36:158-61.

15 Brown AH, Dougenis D. Dissection of the two internal mammary arteries with maximal exposure and minimal adverse sequelae by means of an inexpensive, simple atraumatic retractor. F Thorac Cardiovasc Surg 1991;102:753-6.

16 Kaplan EL, Meier P. Nonparametric estimation from incomplete observation. F Am Stat Assoc 1958:53:457-81.

17 Mantel N, Haenszel W. Statistical aspects of the analysis of data from retrospective studies. F Natl Cancer Inst 1959;22: 719-48.

18 Dougenis D, Robinson MC, Brown AH. Acute dissection of the internal mammary artery: a fatal complication of coronary artery bypass grafting. F Cardiovasc Surg 1990;31: $589-91$

19 Foster ED. Reoperation for coronary artery disease. Circulation 1985;72(suppl 5):59-64.

20 Loop FD, Lytle MW, Gill CC, et al. Trends in selection and results of coronary artery reoperation. Ann Thorac Surg 1983;36:380-4

21 Lytle BW, Loop FD, Cosgrove DM. Fifteen-hundred coronary reoperations. Results and determinants of early and late survival. F Thorac Cardiovasc Surg 1987;93:84759.

22 Cameron A, Kemp HG, Green GE. Reoperation for coronary artery disease. Ten years of clinical follow-up. Circulation 1988;78(suppl 1):158-62.

23 Foster ED, Fisher LD, Kaiser GC, et al. Principal investigators of CASS and their associates. Comparison of operative mortality and morbidity for initial and repeat coronary artery bypass graft: The coronary artery surgery study (CASS) registry experience. Ann Thorac Surg 1984;38: 563-70.

24 Noppeney T, Eberlein V, Langhans L, et al. The influence of the age and other risk factors on the results of coronary reoperation. Thorac Cardiovasc Surg 1993;41:43-8.

25 Pidgeon J, Brooks N, Magree P, et al. Reoperation for angina after previous aortocoronary bypass surgery. Br Heart $\mathcal{f}$ 1987;53:269-75.

26 Loop FD. Internal thoracic artery grafts. Biologically better coronary arteries. N Engl f Med 1996;334:263-5.

27 Cameron A, Davis KB, Green G, et al. Coronary bypass surgery with internal thoracic artery grafts. Effects on survival over a 15-year period. $N$ Engl $\mathcal{f}$ Med 1996;334:21619.

28 Schmuziger M, Christenson JS, Maurise J, et al. Reoperative myocardial revascularization: analysis of 458 reoperations and 2645 single operations. Cardiovasc Surg 1991;2:633-9.

29 Rosengart TK. Risk analysis of primary versus reoperative coronary artery bypass grafting. Ann Thorac Surg 1993; 56(suppl 5):74-7.

30 Savage EB, Cohn LH. "No-touch" dissection, antegraderetrograde blood cardioplegia and single aortic cross-clamp significantly reduce operative mortality of reoperative CABG. Circulation 1994;90:140-3.

31 Loop FD. A 20 -year experience in coronary artery reoperation. Eur Heart f 1989;10(suppl H):78-84.

32 Dougenis D, Serin N, Brown AH. Repeated coronary surgery for recurrent angina. Is it cost-effective? Eur Heart f 1992;13:9-14.

33 Carrier M, Gregoire J, Tronc F, et al. Effect of internal mammary artery dissection on sternal revascularization. Ann Thorac Surg 1993;55:803-4. 